\title{
A Longitudinal Study into the New and Long-Term Use of Self-monitoring Blood Glucose Strips in the UK
}

\author{
C. L. Morgan · A. Griffin · G. H. Chamberlain · A. Turkiendorf · P. McEwan · L. M. Evans · D. R. Owens
}

Accepted: April 7, 2010 / Published online: July 28, 2010

(C) The Author(s) 2010. This article is published with open access at Springerlink.com

\section{ABSTRACT}

Aims: To determine the impact of selfmonitoring blood glucose (SMBG) strip use in patients with type 2 diabetes in the UK. Methods: The study period was April 1, 2004 to July 31,2005 . Data from primary care was extracted from The Health Improvement Network database. Patients identified with diabetes and matching the inclusion criteria were defined as new users of SMBG, prevalent users, or non-users. Patients were also defined as treated with insulin, with oral agents (OA), or not pharmacologically

C. L. Morgan $(\bowtie) \cdot$ G. H. Chamberlain · A. Turkiendorf • P. McEwan

Cardiff Research Consortium, Cardiff, Medicentre, Cardiff, CF14 4UJ, UK.

E-mail: chris.morgan@chks.co.uk

A. Griffin

LifeScan EMEA, High Wycombe, UK

L. M. Evans

Llandough Diabetes Centre, University Hospital

Llandough, UK

D. R. Owens

School of Medicine, Cardiff University, Cardiff, UK treated. Change in glycosylated hemoglobin $\left(\mathrm{HbA}_{1 \mathrm{c}}\right)$ at baseline and after 12 months was compared. Results: 2559 patients met the inclusion criteria. For new users, $\mathrm{HbA}_{1 \mathrm{c}}$ fell by $0.59 \%(P=0.399)$ for those treated with insulin, $1.52 \%(P<0.001)$ for those treated with $\mathrm{OA}$, and $0.51 \%(P<0.001)$ for no treatment. In prevalent users, changes were $0.31 \%(P<0.001), 0.34 \%(P<0.001)$, and $0.09 \%(P=0.456)$, respectively. In nonusers, changes were $0.28 \%(P=0.618), 0.42 \%$ $(P<0.001)$, and an increase of $0.05 \%(P=0.043)$, respectively. A significant decrease in mean $\mathrm{HbA}_{1 \mathrm{c}}$ was associated with increasing strip use in OA patients newly initiated on strips. Conclusion: This observational study showed a significant decrease in $\mathrm{HbA}_{1 \mathrm{c}}$ for new users of SMBG treated either non-pharmacologically or with OA, and for prevalent users treated with insulin or OA. Reduced $\mathrm{HbA}_{1 \mathrm{c}}$ with increasing strip use was observed but was only significant for OA-treated new users. This suggests that SMBG use has a role in the treatment of non-insulin treated patients with type 2 diabetes.

Keywords: blood glucose strips; self-monitoring; type 2 diabetes 


\section{INTRODUCTION}

The importance of glycemic control for patients with type 2 diabetes has been well documented. ${ }^{1}$ Current guidance in both the UK and the US recommends the use of selfmonitoring blood glucose (SMBG) for both insulin and non-insulin treated type 2 diabetes. ${ }^{2,3}$ There is, however, continuing debate as to the role of SMBG in the management of patients with non-insulin treated type 2 diabetes. ${ }^{4,5}$

Data from randomized controlled trials are both confusing and contradictory, predominantly due to differences in study design and the inability to measure the impact of SMBG use in isolation to different treatment and management change algorithms. ${ }^{6,7}$ Studies based on observational data are equally inconsistent. A report based on the Fremantle Diabetes Study described no difference in glycosylated hemoglobin $\left(\mathrm{HbA}_{1 \mathrm{c}}\right)$ between those using SMBG and those who were not, ${ }^{8}$ whereas a study based in the United States showed a significant reduction in $\mathrm{HbA}_{1 \mathrm{c}}$ for those patients newly initiated on SMBG and those patients already using strips treated with either insulin or oral hypoglycemic agents (OA). ${ }^{9}$ Furthermore, this study also demonstrated a significant dose response between frequency of SMBG usage and reduction in $\mathrm{HbA}_{1 \mathrm{c}}$.

There is a cost to providing $\mathrm{SMBG},{ }^{4}$ but this may prove cost-effective when improved management is offset by the reduction of diabetes-related complications. ${ }^{10}$ There have also been concerns about the potential negative psychological impact upon patients of using SMBG. ${ }^{11,12}$ However, this has been countered with claims that the use of SMBG allows for the empowerment of patients and enables them to have a greater understanding of their condition and how it is affected by medication and their lifestyle choices. Nevertheless, SMBG use requires the patient and/or carer to act appropriately on the results, otherwise no benefit will accrue.

A previous cohort study by Karter et al. ${ }^{13}$ sought to assess the longitudinal association between SMBG and glycemic control in diabetic patients within a US health plan (Kaiser Permanente, Northern California, USA). The study reported reductions in $\mathrm{HbA}_{1 \mathrm{c}}$ for new users of SMBG, compared with non-users, although it was acknowledged that it did not control for dose escalation during the study period and, as such, could not isolate the impact of initiation of SMBG.

The aim of this study was to characterize patterns of SMBG use, treatment, and associated $\mathrm{HbA}_{1 \mathrm{c}}$ values in patients with type 2 diabetes within a UK setting, based on the findings from the Karter Study. ${ }^{13}$

\section{MATERIALS AND METHODS}

\section{Data Sources}

Data used in this study were provided by The Health Improvement Network ${ }^{14}$ database, which is a longitudinal research database derived from over 350 primary care practices in the UK and has records for approximately 6 million patients. ${ }^{15}$

\section{Inclusion Criteria}

The study period was based on April 1, 2004 to July 31, 2005. Patients included in the study were those with a diagnosis of type 2 diabetes recorded in their medical history using the Read Code classification between 2002 and 2007, and a $\mathrm{HbA}_{1 \mathrm{c}}$ test result recorded in the 90 days (inclusive) before baseline and the final quarter of the study period (between 273-365 days after baseline). For patients using SMBG, baseline $\mathrm{HbA}_{1 \mathrm{c}}$ was defined as the date of the first prescription during the study period. For non- 
strip users, baseline was defined arbitrarily as the December 1, 2004.

Only patients prescribed the same combinations and dosages of oral and/or insulin treatment in the quarter before baseline and final quarter were included. Patients were excluded if they had a history of end-stage renal failure or a test result of serum creatinine $\geq 200 \mu \mathrm{mol} / \mathrm{L}$ recorded in their patient history.

\section{Cohort Definitions}

Patients were classified by SMBG use according to the nomenclature defined by Karter et al., ${ }^{13}$ based upon British National Formulary codes recorded in the patient's prescription records. "Prevalent users" were those with at least one strip prescription before baseline date, and at least two separate prescriptions during the study period. "New users" were those with at least two separate prescriptions in the study period and no strips prescribed in the year before baseline. "Non-users" were those with no SMBG strips prescribed either before baseline or during the study period.

Patients were also classified according to therapy regimen based upon prescription records using the British National Formulary definitions. The "no medication" group were those patients with no prescriptions (either insulin or $\mathrm{OA}$ ) recorded in the 90 days before baseline and the final quarter of the study. "OA" (oral agents only) were those patients prescribed at least one $\mathrm{OA}$ and no insulin prescription in the 90 days before baseline and the final quarter of the study. The "insulin" group were those patients prescribed at least one insulin agent, either on its own or in combination with OA at the quarter pre-baseline and the final quarter of the study period. Patients changing their total insulin dosage or OA dosage between these periods were excluded.

\section{Statistical Analysis}

Changes in mean $\mathrm{HbA}_{1 \mathrm{c}}$ before and 12-months post-baseline were compared using the paired $t$-test. To evaluate the change in $\mathrm{HbA}_{1 \mathrm{c}}$ associated with different volumes of strips use, mixedeffects multi-level models were created that allowed for the change in $\mathrm{HbA}_{1 \mathrm{c}}$ to be analyzed at multiple hierarchical levels, that is: strip category $(<0.5 / 0.5-1 />1)$, age, sex, duration of diabetes, baseline $\mathrm{HbA}_{1 \mathrm{c}}$, and primary care practice. Due to the relatively small number of patients in the insulin groups when disaggregated by strip frequency, this analysis was restricted to those patients treated either with oral agents or who were not receiving pharmacological intervention. The variables were assumed to stand behind the fixed effects, whereas random effects were put on the primary care variable.

\section{RESULTS}

From a total of 31,667 patients with type 2 diabetes, 2559 (8.1\%) met the inclusion criteria as shown in Figure 1.

Demographic characteristics, duration of diabetes, baseline $\mathrm{HbA}_{1 \mathrm{c}}$, and mean daily SMBG strip usage by therapy type and SMBG use is shown in Table 1. For each treatment group (no treatment, OA, and insulin), baseline $\mathrm{HbA}_{1 \mathrm{c}}$ was higher for patients newly initiated on SMBG compared with non-users/prevalent users, although this was only significant for the OA group $(P<0.001)$. It was lowest for those patients who were non-users of SMBG. The new user groups were also younger with a shorter duration of diabetes.

SMBG was most commonly used by patients treated with insulin $(n=271)$, of which $98.5 \%$ of these patients were either new or prevalent users. Conversely, it was least common in those who were receiving no medication $(n=293$ [29.8\%]). 
Figure 1. Derivation of study cohort and grouping by self-monitoring blood glucose usage and treatment regimen. $\mathrm{HbA}_{\mathrm{lc}}=$ glycosylated hemoglobin; $\mathrm{OA}=$ oral agents.

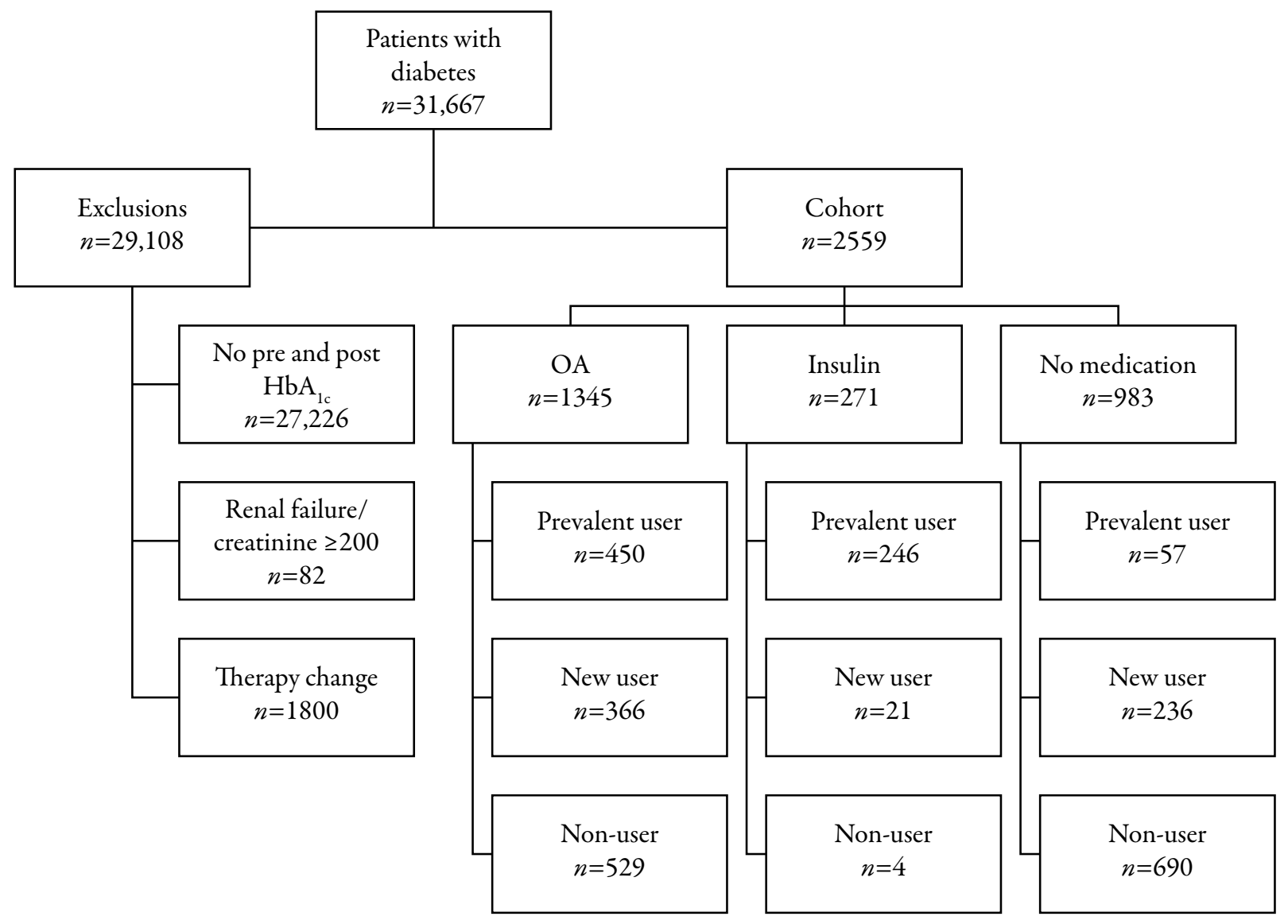

Figure 2. Change in mean baseline $\mathrm{HbA}_{1 \mathrm{c}}$ for patients by self-monitoring blood glucose use and treatment. ${ }^{*} P<0.001$. $+P<0.05 . \mathrm{HbA}_{1 \mathrm{c}}=$ glycosylated hemoglobin; $\mathrm{OA}=$ oral agents.

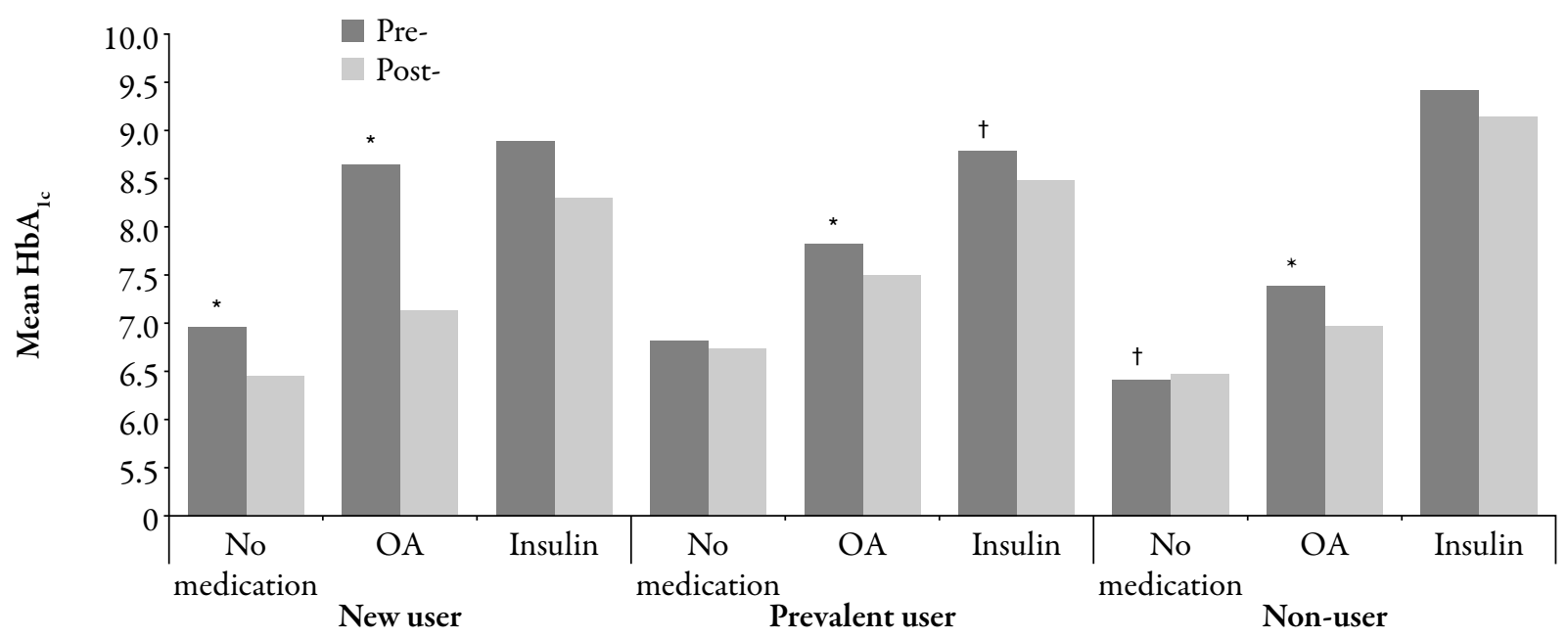




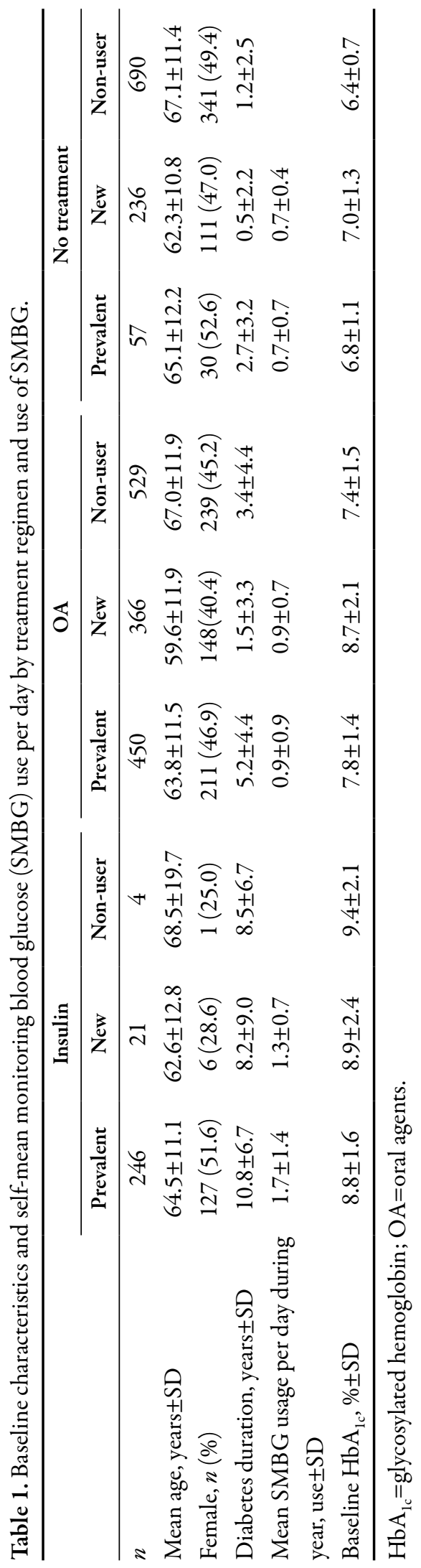

Figure 3. Change in $\mathrm{HbA}_{\mathrm{lc}}$ between baseline and 12 months by treatment group and daily self-monitoring blood glucose use in newly initiated patients. ${ }^{*} P<0.05$. $\mathrm{HbA}_{1 \mathrm{c}}=$ glycosylated hemoglobin; $\mathrm{OA}=$ oral agents .

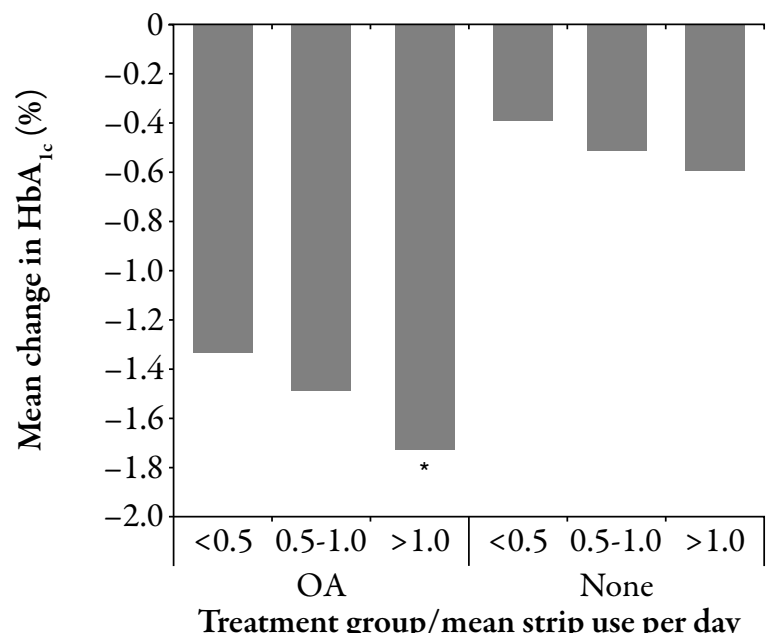

Figure 4. Change in $\mathrm{HbA}_{1 \mathrm{c}}$ between baseline and 12 months by treatment group and daily self-monitoring blood glucose use in prevalent patients. ${ }^{*} P<0.05$. $\mathrm{HbA}_{1 \mathrm{c}}=$ glycosylated hemoglobin; $\mathrm{OA}=$ oral agents.

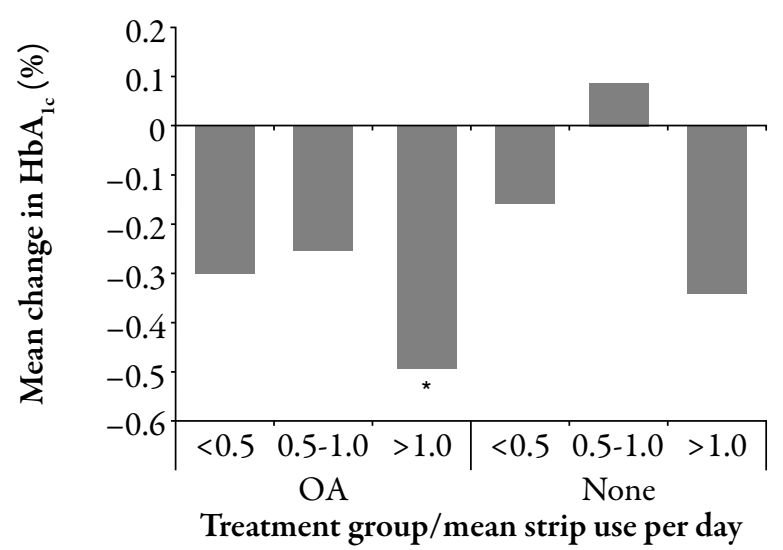

\section{Change in $\mathrm{HbA}_{1 \mathrm{c}}$}

Figure 2 shows the change in $\mathrm{HbA}_{1 \mathrm{c}}$ before and after baseline by treatment type and SMBG use. For new users, $\mathrm{HbA}_{1 \mathrm{c}}$ fell by $0.59 \%(P=0.399)$ for those patients treated with insulin, $1.52 \%$ $(P<0.001)$ for those patients treated solely by OA, and $0.51 \%(P<0.001)$ for those patients receiving no treatment. In the prevalent users, $\mathrm{HbA}_{1 \mathrm{c}}$ fell 
by $0.31 \%(P<0.001)$ for those patients treated with insulin, $0.34 \%(P<0.001)$ for those patients treated solely by $\mathrm{OA}$, and by $0.09 \%(P=0.456)$ for those patients receiving no treatment.

In the non-user group, $\mathrm{HbA}_{1 \mathrm{c}}$ fell by $0.28 \%$ $(P=0.618)$ for those patients treated with insulin, $0.42 \%(P<0.001)$ for those patients treated solely with OA and increased by $0.05 \%(P=0.043)$ for those patients receiving no treatment.

\section{Change Associated with SMBG Strip Use}

Mean SMBG strip use for insulin-treated patients was lower for newly initiated rather than prevalent SMBG users (1.24 versus 1.73 strips per day, $P=0.010)$. For the OA group, mean strips used per day was 0.84 for new users, compared with 0.86 for prevalent users $(P=0.689)$. For the non-medication group, the mean strips used per day was 0.69 for new users, compared with 0.74 for prevalent users ( $P=0.628)$.

Figures 3 and 4 show the change in $\mathrm{HbA}_{1 \mathrm{c}}$ associated with different volumes of strip use by treatment groups for newly initiated and prevalent strip users, respectively, for those patients receiving either oral treatment or no treatment after adjusting for age, sex, baseline $\mathrm{HbA}_{1 \mathrm{c}}$, and duration of diabetes in the fixedeffects model.

There was a significant decrease in mean $\mathrm{HbA}_{1 \mathrm{c}}$ associated with increasing strip use in those patients newly initiated on strips, for patients in the OA group using greater than 1 strip per day. In the prevalent user groups there was a pattern of reduced $\mathrm{HbA}_{1 \mathrm{c}}$ associated with increased strip use for both treatment groups, but this was not significant.

\section{DISCUSSION}

This study aimed to replicate and improve upon the US study by Karter et al., ${ }^{13}$ which determined the impact of SMBG use upon $\mathrm{HbA}_{1 \mathrm{c}}$ for both newly initiated and prevalent users. Unlike this previous study, we were able to limit our analysis to those patients whose medication remained constant over the study period. As in the Karter ${ }^{13}$ study, there was a decrease in $\mathrm{HbA}_{1 \mathrm{c}}$ for all new users regardless of therapy regimen following initiation of SMBG, although this was not significant for those patients prescribed insulin. For prevalent users we showed a significant decrease for those using insulin and OA, although there was a pattern of reduced $\mathrm{HbA}_{1 \mathrm{c}}$ with greater strip use in the non-pharmacologically treated group.

For patients not using SMBG, there was a significant decrease in $\mathrm{HbA}_{1 \mathrm{c}}$ only in those patients prescribed OA. For patients who did not receive pharmacological intervention, there was a significant increase in $\mathrm{HbA}_{1 \mathrm{c}}$. Whilst there was a pattern of reduced $\mathrm{HbA}_{1 \mathrm{c}}$ with increasing strip use, this was only significant for new users on OA. It should also be noted that unlike the majority of insulin users, who will use a broadly consistent number of strips each day, patients on OA or diet and exercise may perform intermittent glucose profiling, where they would test four or more times a day for a week, and then not test for a period. The "dose response" in the OA group may therefore indicate a frequency of glucose profiling rather than an absolute number of tests per day.

This was an observational study based on treatment patterns observed in primary care. As such it offers a "real world" picture of the impact of SMBG use in everyday practice. However, we accept that as it did not have the randomization that would occur in a controlled trial there may have been differences between those patients prescribed SMBG and may have confounded our results. Such differences may include patient compliance and motivation and physician preference. However, unlike 
Karter, ${ }^{13}$ in this study we were able to compare patients who remained on the same therapy regimen before and after initiation of SMBG. Clearly, the motivation to initiate SMBG, either by the patient or physician, will be the need to maintain glycemic control and so may be accompanied by changes in therapy.

Karter et al. ${ }^{13}$ highlighted the potential for reverse causality and we noted similar observations in our study-notably that the non-SMBG patients had lower $\mathrm{HbA}_{1 \mathrm{c}}$ at baseline than new users. As such, poor glycemic control may be the trigger for SMBG use with accompanying intensification of educational interventions. In both patients treated with OA and those managed by diet and exercise, new users of SMBG had higher $\mathrm{HbA}_{1 \mathrm{c}}$ values than the non-user groups, suggesting that prescribers had criteria (explicit or implicit) in determining when (and why) to initiate a patient on to SMBG. Furthermore, both groups also showed a significant decrease in $\mathrm{HbA}_{1 \mathrm{c}}$ following initiation of SMBG. One criticism of SMBG studies is that it cannot be determined to what extent initiation of strips was accompanied by educational interventions which may have been different to those received by non-users. It should, however, be acknowledged that SMBG use in itself is not a therapeutic intervention, but an insight to glucose control. In that context it makes sense that a patient that is being "educated" to improve control of their diabetes might receive SMBG as a tool to provide awareness of glucose levels and therefore seen as part of that education. This raises the issue as the extent to which the patient uses the data afforded to them from their SMBG monitoring. It could potentially be the process of testing itself which by reinforcing the presence of diabetes to the patient leads to increased awareness of the need to maintain glucose control. This question, however, cannot be addressed by this study.

The implication that poor glycemic control is one potential trigger for SMBG fits with the recent National Institute for Health and Clinical Excellence clinical guidelines ${ }^{2}$ on the management of type 2 diabetes, where it recommends that SMBG be offered to persons newly diagnosed with type 2 diabetes only as an integral part of his or her self-management education. Furthermore, the observation that patients do not routinely start SMBG until they start to lose glycemic control may partly explain the conflicting results revealed by clinical trials investigating the impact of SMBG in non-insulin users. For example, patients in the Diabetes Glycemic Education and Monitoring (DiGEM) study, ${ }^{16}$ with a mean $\mathrm{HbA}_{1 \mathrm{c}}$ at baseline of approximately $7.5 \%$, observed no benefit from SMBG in noninsulin treated patients, compared with the Auto-Surveillance Intervention Active (ASIA) study, ${ }^{17}$ reporting a mean baseline $\mathrm{HbA}_{1 \mathrm{c}}$ of around 9\%, which did observe a benefit.

This study demonstrated that SMBG use was associated with lower $\mathrm{HbA}_{1 \mathrm{c}}$ in nonpharmacologically treated patients who were new users but not in prevalent users. This might indicate that SMBG is of benefit initially in informing the patient about his or her $\mathrm{HbA}_{1 \mathrm{c}}$ levels and how this can be affected by a patient's exercise and diet regimes. Over a longer time period, this may be limited either due to the reduced impact of diet and exercise to control $\mathrm{HbA}_{1 \mathrm{c}}$ over time or perhaps changes in patients' behavior after the initial "novelty" of monitoring and reacting to $\mathrm{HbA}_{1 \mathrm{c}}$ readings.

Whereas some guidelines are moving away from recommending SMBG use in patients not treated with insulin, this study, and that of Karter, ${ }^{13}$ may indicate that SMBG use in 
some subgroups of non-insulin-using patients is beneficial, at least initially, as a means of allowing a patient to understand his or her condition and the impact of behaviors upon it.

\section{CONCLUSION}

This observational study showed a significant decrease in $\mathrm{HbA}_{1 \mathrm{c}}$ for new users of SMBG treated either non-pharmacologically or with OA, and for prevalent users treated with insulin or OA. Reduced $\mathrm{HbA}_{1 \mathrm{c}}$ with increasing strip use was observed, but was only significant for OA treated new users. This suggests that SMBG use has a role in the treatment of non-insulin-treated patients with type 2 diabetes.

\section{ACKNOWLEDGMENTS}

Christopher Morgan, George Chamberlain, Andrzej Tukiendorf, and Phil McEwan all work for Cardiff Research Consortium, which received funding to conduct this study from LifeScan EMEA. Adrian Griffin is an employee of LifeScan EMEA. Marc Evans has no conflicting interest in relation to this paper. David Owens has received research support from Sanofi-Aventis and Novo Nordisk. He has served on the clinical advisory board for Roche Diagnostics, Sanofi-Aventis, Novo Nordisk, Merck Sharpe and Dohme, and Pfizer and has served as a consultant for Novo Nordisk and Sanofi-Aventis. He has received honoraria from all the above for consultancy and lecture fees.

Open Access. This article is distributed under the terms of the Creative Commons Attribution Noncommercial License which permits any noncommercial use, distribution, and reproduction in any medium, provided the original author(s) and source are credited.

\section{REFERENCES}

1. UK Prospective Diabetes Study Group. Intensive blood-glucose control with sulphonylureas or insulin compared with conventional treatment and risk of complications in patients with type 2 diabetes. (UKPDS 33). Lancet. 1998;352:837-853.

2. National Institute for Health and Clinical Excellence. Type 2 diabetes. National clinical guideline for management in primary and secondary care (update). London: NICE, 2008 Available at: www.nice.org.uk/nicemedia/pdf/ CG66NICEGuideline.pdf. Accessed April 13, 2010.

3. American Diabetes Association. Standards of medical care in diabetes. Diabetes Care. 2005;28(suppl. 1):S4-S36.

4. Davidson MB. Counterpoint: self-monitoring of blood glucose in type 2 diabetic patients not receiving insulin: a waste of money Diabetes Care. 2005;28:1531-1533.

5. Klonoff DC, Bergenstal R, Blonde $\mathrm{L}$, et al. Consensus report of the Coalition for Clinical Research-self-monitoring of blood glucose. J Diabetes Sci Technol. 2008;2:1030-1053.

6. Klonoff DC. New evidence demonstrates that selfmonitoring of blood glucose does not improve outcomes in type 2 diabetes-when this oractice is not applied properly. J Diabetes Sci Technol. 2008;2:342-348.

7. Welschen LMC, Bloemendal E, Nijpels G, et al. Selfmonitoring of blood glucose in patients with type 2 diabetes who are not using insulin: a systematic review. Diabetes Care. 2005;28:1510-1517.

8. Kempf K, Neukirchen W, Martin S, Kolb H. Selfmonitoring of blood glucose in type 2 diabetes: a new look at published trials. Diabetologia. 2008;51:686-688.

9. Davis WA, Bruce DG, Davis TME. Is self-monitoring of blood glucose appropriate for all type 2 diabetic patients? Diabetes Care. 2006;29:1764-7170.

10. Palmer AJ, Dinneen S, Gavin JR III, Gray A, Herman WH, Karter AJ. Cost-utility analysis in a UK setting of self-monitoring blood glucose in patients with type 2 diabetes. Curr Med Res Opin. 2006;22:861872.

11. Gallichan M. Self monitoring of glucose by people with diabetes: evidence based practice. BMJ. 1997;314:964-967. 
12. O'Kane MJ, Bunting B, Copeland M, Coates VE. Efficacy of self monitoring blood glucose in patients with newly diagnosed type 2 diabetes (ESMON study): randomised controlled trial. BMJ. 2008;336:1174-1177.

13. Karter AJ, Parker MM, Moffet HM, et al. Longitudinal study of new and prevalent use of self monitoring of blood glucose. Diabetes Care. 2006;29:1756-1763.

14. The Health Improvement Network. About us. Available at: www.thin-uk.com/partnership.htm. Accessed April 8, 2010.

15. Maguire A, Blak B, Thompson M. The importance of defining periods of complete mortality reporting for research using automated data from primary care. Pharmacoepidemiol Drug Saf. 2008;18: 76-83.

16. Farmer A, Wade A, Goyder E, et al. Impact of self monitoring of blood glucose in the management of patients with non-insulin treated diabetes: open parallel group randomised trial. BMJ. 2007;335:132.

17. Guerci B, Drouin P, Grangé V, et al. Selfmonitoring of blood glucose significantly improves metabolic control in patients with type 2 diabetes mellitus: the Auto-Surveillance Intervention Active (ASIA) study. Diabetes Metab. 2003;29:587-594. 